\title{
2
}

\section{Continuous Model Simulations to Develop a Phased Approach for SSO Control in Piqua, Ohio}

\section{Benjamin I. Gamble, Derek D. Wride and Dave Burtner}

The City of Piqua, Ohio, initiated a study to develop an alternative for meeting regulatory requirements regarding an active sanitary sewer overflow (SSO) in its wastewater collection system. Continuous hydraulic model simulations were used to study how to reduce the frequency of the city's SSO. The U.S. Environmental Protection Agency's Storm Water Management Model (SWMM) version 5 built upon the city's existing model and validated the model based on reported annual SSO activity using continuous simulations. The city's collection system includes $192 \mathrm{~km}$ sanitary sewers. The city's wastewater treatment plant (WWTP) accepts an average flow of $175 \mathrm{~L} / \mathrm{s}$. Five-year continuous simulations were used to assess performance of an alternative that included an equalization (EQ) basin to store excess wet weather flows (WWFs) to greatly reduce SSO. The modeling identified existing system hydraulic capacity limitations and helped to optimize the EQ basin alternative. Optimization included using the model to identify an EQ basin location that uses gravity-in/gravity-out operation, minimizing infrastructure modifications. The continuous simulation approach resulted in a phased alternative and corresponding conceptual design that will provide the city with flexibility in controlling SSO.

Gamble, B., D. Wride and D. Burtner. 2010. "Continuous Model Simulations to Develop a Phased Approach for SSO Control in Piqua, Ohio." Journal of Water Management Modeling R236-02. doi: 10.14796/JWMM.R236-02.

(C) CHI 2010 www.chijournal.org ISSN: 2292-6062 (Formerly in Dynamic Modeling of Urban Water Systems. ISBN: 978-0-9808853-3-0) 


\subsection{Problem/Challenge}

The City of Piqua, Ohio, is working with regulators to develop a phased approach for eliminating its single structural SSO. This approach will provide the city with financial flexibility in addressing infrastructure improvements needed to eliminate the SSO. Part of this challenge includes identifying system deficiencies, siting a $3780 \mathrm{~m}^{3}$ EQ basin, determining the basin's operational configuration, and projecting the amount of storage that will be needed to eliminate the SSO.

\subsection{Methodology}

The city's existing hydraulic model was used to perform continuous simulations. The continuous simulation method applies historic rainfall events to the model and routes flows through the collection system. Continuous simulation shows how future system infrastructure will operate based on historic information; this can yield more robust results than a design storm approach. Historic rainfall data from 2000 to 2004 were selected for the continuous simulation modeling. This 5 y time period coincides with SSO regulatory reporting conducted by the city, which was used for model validation. Continuous simulations use the hydraulic model to simulate results of back-to-back rainfall events utilizing actual historic events that occurred in the city. Average annual rainfall for the $5 \mathrm{y}$ period was $802.6 \mathrm{~mm}$., compared to a $50 \mathrm{y}$ historic average of $760.1 \mathrm{~mm}$. and includes five of the largest 21 rainfall events by volume from the same 50 y period.

The continuous simulation method allowed this study to focus on two aspects associated with a proposed EQ basin: (i) annual SSO activity based on various EQ basin volumes, and (ii) EQ basin utilization statistics. Previous efforts by the city indicated that a $3780 \mathrm{~m}^{3} \mathrm{EQ}$ basin is needed to meet a certain level of design storm protection. The current study utilized the $5 \mathrm{y}$ simulations coupled with EQ basin storage sizes that ranged from zero to $18900 \mathrm{~m}^{3}$ of storage. This process also provided a basis for analyzing the existing nearby siphons and how they would influence basin performance. Basin utilization statistics were developed for the $3780 \mathrm{~m}^{3}$ EQ basin. The utilization statistics will be helpful in determining if there is a benefit to providing smaller compartments within the proposed basin in an effort to reduce operation and maintenance (O\&M) costs.

The continuous simulation method also aided in developing a conceptual design for the EQ basin. The model was used to evaluate different operational 
configurations, such as pump-in/gravity-out, gravity-in/pump-out, and gravityin/gravity-out. This process aids in identifying proposed infrastructure that minimizes capital and O\&M expenditures.

Key elements of the effort were the availability of a calibrated model of the wastewater collection system, SSO records spanning several years, local hourly precipitation data, and WWTP operator control strategies. The city had previously completed a study that calibrated a skeletalized model incorporating pipes with diameters $\geq 533 \mathrm{~mm}$. The previous calibration used flow monitoring data from the wastewater collection system. To support the continuous simulation approach, SSO records were used to validate the model. SSO records were used to compare annual overflow frequency against continuous simulation results. WWTP operator control strategies were also used in validating the model during wet weather events. The WWTP operator closes and opens gates at the WWTP headworks from two influent interceptors. Knowledge of how the gates are operated during wet weather is critical for setting up a control strategy in the model. When wastewater depth reaches $5.33 \mathrm{~m}$ at the WWTP headworks, a gate to one of the interceptors closes. This was critical information, since wet weather flows are the driving factor for this effort and aided in the calibration to reported SSO activity.

\subsection{Collection System and Results}

Figure 2.1 shows a plan view of pertinent collection system features. System drainage is generally south and east toward the WWTP. Two main interceptors, West and Miami River, convey the majority of wastewater to the WWTP. The West interceptor is $914.4 \mathrm{~mm}$ diameter and the Miami River interceptor is $1.067 \mathrm{~m}$ diameter. The SSO is located along the West interceptor and is just upstream of twin siphons that are $405 \mathrm{~mm}$ diameter.

Figure 2.2 illustrates the profile of the existing interceptors from the WWTP upstream to the SSO location. Two key items are: (i) the pipe sizes in the vicinity of the twin siphons, and (ii) the available head range between the West and Miami River interceptors. The twin siphons have $<50 \%$ of the conveyance capacity of the upstream influent pipe. The figure also shows the $2.59 \mathrm{~m}$ invert to crown elevation difference between the two interceptors. This played an important role in the EQ basin operational configuration as it allows gravityin/gravity-out operation for the EQ basin and allows the basin to be close to the WWTP. Being near the WWTP keeps the basin away from dense urban development, and reduces operator travel time between the basin and the WWTP. 


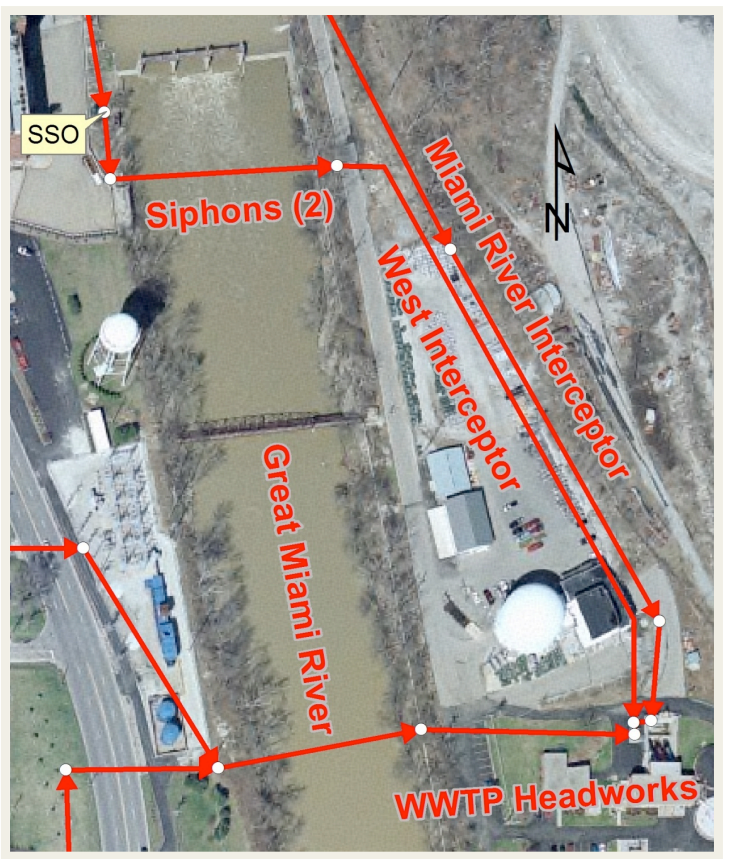

Figure 2.1 Pertinent collection system features.

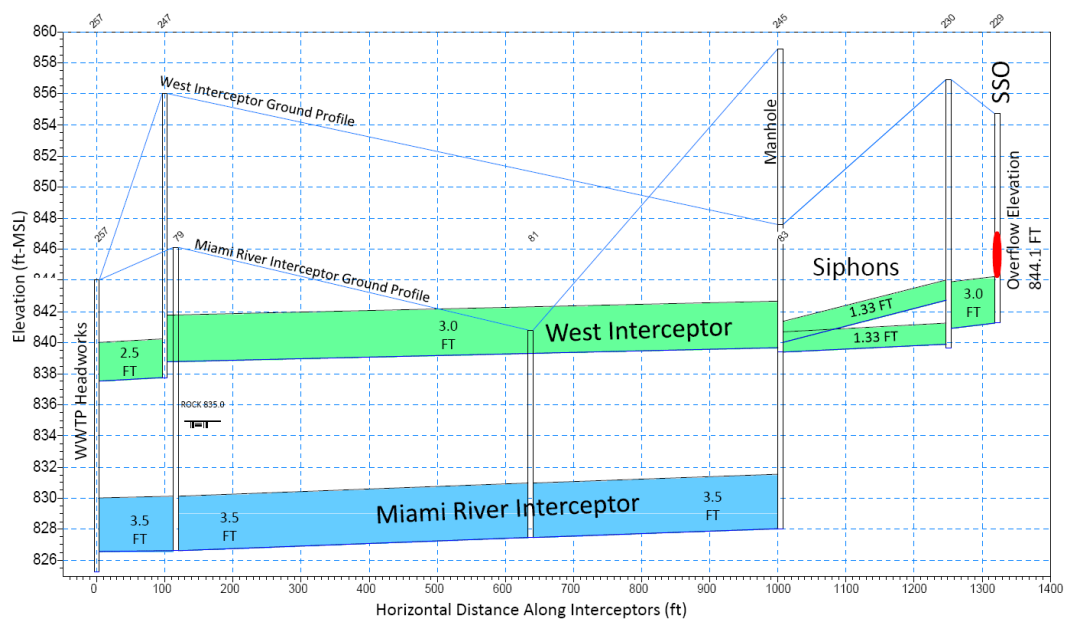

Figure 2.2 Profile of existing interceptors. 
Figure 2.3 illustrates the conceptual layout for gravity-in/gravity-out operation. To achieve a $3780 \mathrm{~m}^{3} \mathrm{EQ}$ basin, the conceptual size would be $2.438 \mathrm{~m}$ tall and $44.50 \mathrm{~m}$ diameter. The EQ basin would operate by diverting excess flow from the West interceptor into the basin. Excess flow would then be stored until wet weather events pass, at which time the basin could be dewatered as the system allows. Dewatering the EQ basin would be accomplished via gravity flow to the lower elevation Miami River interceptor.

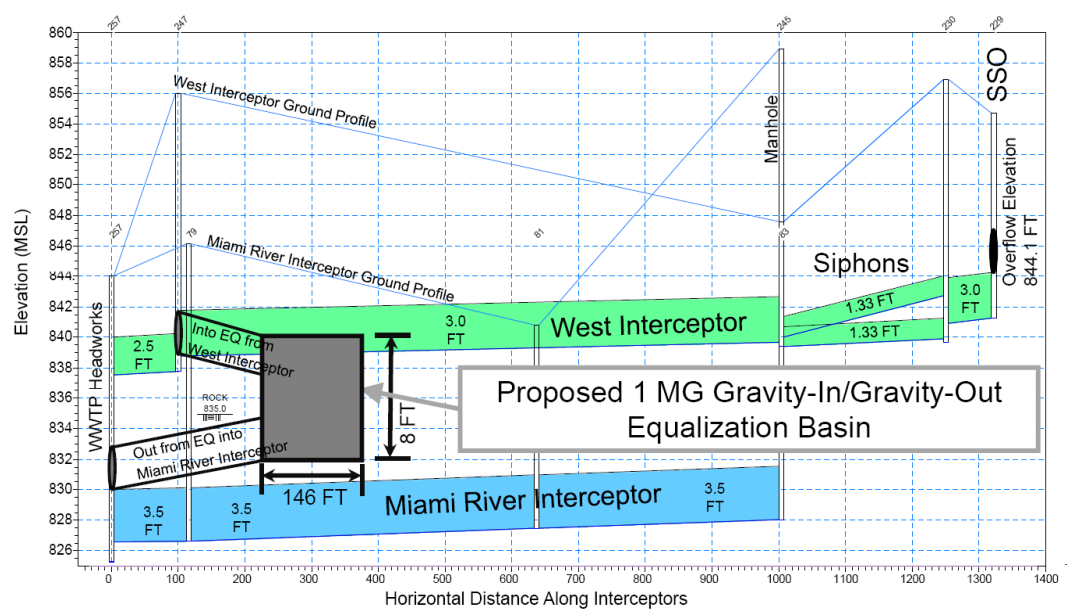

Figure 2.3 Profile of existing interceptors with proposed EQ basin.

This conceptual design was used with continuous simulations to evaluate storage sizes from $0 \mathrm{~m}^{3}$ (existing conditions) up to $3780 \mathrm{~m}^{3}$ to develop a chart for average number of SSOs per year. To achieve this, six different model scenarios were used to represent the incremental storage volumes. Figure 2.4 illustrates the results of the different EQ storage scenarios $<3780 \mathrm{~m}^{3}$. The curve with the dots represents the existing collection and indicates there is no SSO reduction benefit for EQ basin storage $>7560 \mathrm{~m}^{3}$. This is due to siphon capacity on the West interceptor. The siphons do not allow adequate conveyance to the EQ basin to take advantage of the larger storage volumes evaluated. Figure 2.5 profiles the siphons and illustrates the limited capacity and shows approximately $610 \mathrm{~mm}$ headloss across the siphons. 


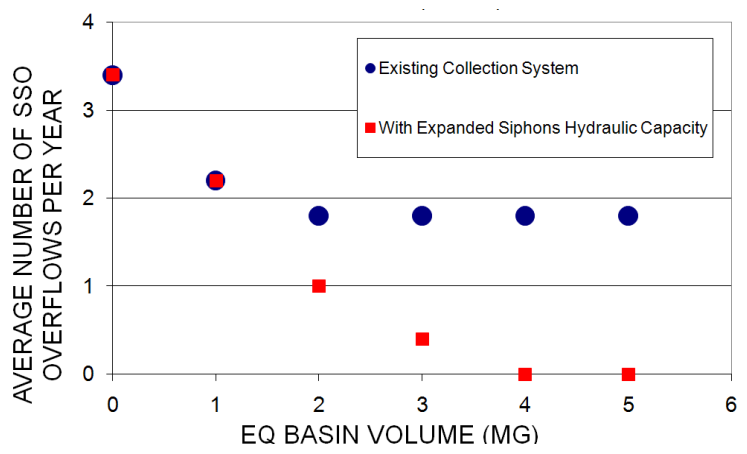

Figure 2.4 Overflow statistics for various volumes based on continuous simulations (2000-2004).

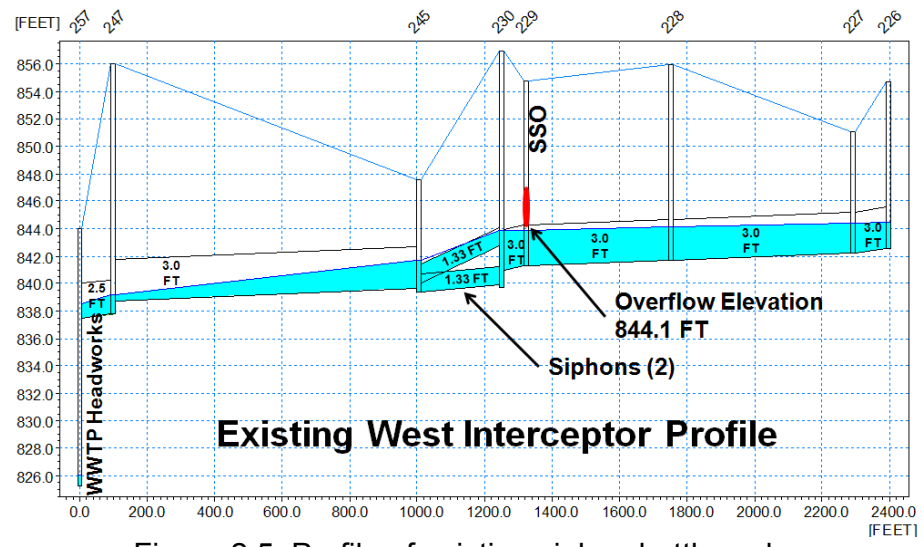

Figure 2.5 Profile of existing siphon bottleneck.

Figure 2.4 also displays results from a similar set of model scenarios where the siphon bottleneck was removed. The curve with the boxes represents the results from this set of scenarios. This curve suggests that the average number of SSOs per year reduces to zero with $11340 \mathrm{~m}^{3}$ to $15120 \mathrm{~m}^{3}$ EQ basin storage. This suggests that in the future, the city should consider installing $7560 \mathrm{~m}^{3}$ to $11340 \mathrm{~m}^{3}$ additional storage after the initial installation of a $3780 \mathrm{~m}^{3}$ basin in order to eliminate the SSO.

To understand how the $3780 \mathrm{~m}^{3}$ EQ basin would be used annually, the corresponding model scenario was reviewed in further detail. The review focused on determining if providing smaller compartments within the $3780 \mathrm{~m}^{3}$ EQ basin would yield cost savings on the O\&M of the facility. Figure 2.6 illustrates 
the results and suggests that the $3780 \mathrm{~m}^{3}$ basin would be used an average of 5 events/y. The graph also suggests that approximately 2.5 events/y would equal or exceed the $3780 \mathrm{~m}^{3}$ storage. Furthermore, the graph suggests that a compartment size of $378 \mathrm{~m}^{3}$ would provide O\&M benefit (lower cleaning frequency) for an average of 1.5 events/y. Providing a smaller $378 \mathrm{~m}^{3}$ compartment inside the $3780 \mathrm{~m}^{3}$ basin would reduce O\&M costs, because only a smaller portion of the basin would need cleaning after smaller events.

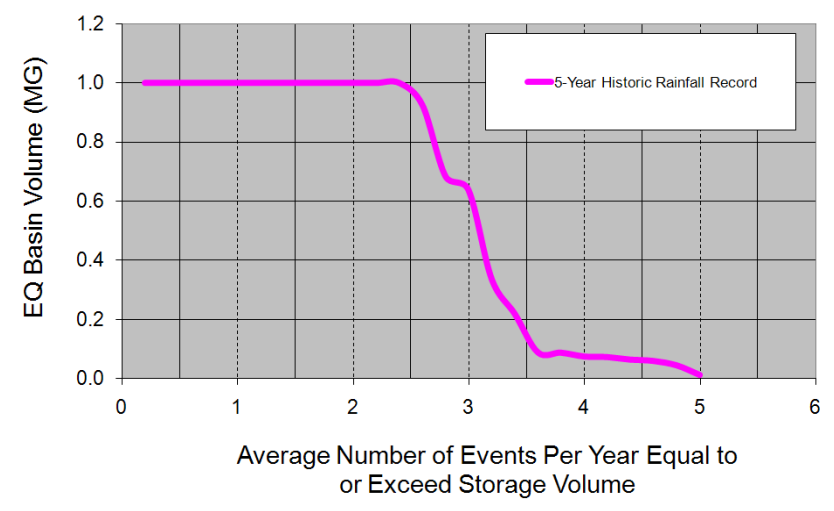

Figure 2.6 Annual basin utilization for $1 \mathrm{MG}$ storage.

\subsection{Conclusions}

The use of continuous simulation modeling led to the phased approach for SSO control in Piqua, Ohio. Key elements of the effort were the availability of a calibrated wastewater collection system model, recent SSO activation records, and local hourly precipitation data. A strength of the continuous simulation approach is that the hydraulic modeling is based on a long term historic local precipitation record and not a synthetic precipitation pattern. The continuous simulation approach also informs analysis of the design, performance, and operation and maintenance of the proposed EQ facility. This phased approach provides the city with flexibility in controlling costs. The phases include:

1. Move forward with installation of initial $3780 \mathrm{~m}^{3} \mathrm{EQ}$ basin;

2. Upgrade the siphons across the Great Miami River in the future; and

3. Install a second EQ basin in the future. 


\section{References}

Huber, W. C. and R. E. Dickinson (1988). Storm Water Management Model-Version 4: User's Manual; Cooperative Agreement CR-811607; U.S. EPA; Athens, Georgia.

Rossman, L.A., R.E. Dickinson, T. Schade, C.C. Chan, E. Burgess, D. Sullivan and F. Lai. 2003. "SWMM 5 - the Next Generation of EPA's Storm Water Management Model." Journal of Water Management Modeling R220-16. doi: 10.14796/JWMM.R220-16.

U.S. EPA (2002). "SWMM Redevelopment Project Plan - Version 5"; U.S. EPA Office of Research and Development - Water Supply and Water Resources Division; Cincinnati, Ohio; February 19, 2002. 